numerous writings have been selected for reprinting in the second section, the most interesting certainly being the text of the physics thesis he submitted for his bachelor's degree at MIT in 1890 . This thesis, devoted to the photography of solar prominences, effectively foretold the main research interest of his life. The final section contains four articles mainly concerned with tracing the development of certain areas of scientific interest to Hale from his own lifetime to the present day. They provide quite useful summaries, but are too brief to allow of treatment in any depth. Moreover, a slight up-dating of some of the contents might have been advisable, since the material in this part of the book was originally presented at a Hale Centennial Symposium in 1968.

The book really must be judged, however, less by its text than by its illustrations. In one sense, indeed, this is a book for the coffee table: the format is large, the layout lavish, and the visual material extensive and attractive. But historians of science have, perhaps, laid too little emphasis on the visual aspects of their subject. It is only fair, therefore, to welcome the quite different stress of this new volume and the additional material on Hale that it provides.

A. J. Meadows

\section{Mighty Whale}

The Whale, Mighty Monarch of the Sea. By Jacques-Yves Cousteau and Philippe Diole. Translated from the French by J. F. Bernard. Pp. 304. (Cassell: London, September 1972.) $£ 2.75$.

DuRING a recent visit to the Smithsonian Museum of Natural History in Washington I expressed to a colleague my admiration for the full-scale model of a blue whale suspended from the ceiling in one of the Museum's galleries, and commented on its similarity to one I had seen only the day before in the New York Natural History Museum. My friend offered the explanation. The resemblance was not accidental, for the New York Museum authorities had borrowed the original mould for the model from the Smithsonian, but to make things a little different they had added an extra foot or so to their whale to lengthen it.

I mention this story because it is indicative of the obsession mankind, even museum curators, has with "bigness", from extra large packets of washing powder to Everest and the Empire State Building. This infatuation with bigness has enabled the whales, and particularly the blue whale, to attract the attention and unfailing admiration of humans. The fascination in whales for man goes back to prehistoric times as is attested by rock and cave paintings; and they have been the subject of writers from the Bible onwards. The great sperm whale fishery of the 18th and 19 th centuries for example provided a wealth of material for literature and spouted Melville's classic Moby Dick, but recently because of the increase in our knowledge of whales and our concern for their diminishing populations books have been coming off the presses in ever-increasing numbers. And so it is not surprising that Jacques-Yves Cousteau has wanted to add his contribution. From him we should have expected a book at least on a par with his The Silent World-alas, The Whale, Mighty Monarch of the Sea comes nowhere near that earlier book either in style or content. At best we can say that there are some useful observations and just occasionally the Cousteau magic shows through, but the author fails to hold the reader's attention and much of the text is not worthy of his talents.

But whatever it lacks in the way of text it more than makes up for this in the illustrations. This volume is a treasure-house of unique and spectacular photographs of whales at the surface of the sea and in it, a collection of pictures which would have been worth publishing on its own. Others may have dived alongside finners and hump-backs but none have brought back gems such as are presented here.

In the past much of our knowledge of whales has been learned from the "bloody" dissections on the decks of factory ships and land stations and perhaps more recently our knowledge of their behaviour has been enhanced by observations in oceanaria. Even so, many questions about these animals remain to be answered, for example, how do whales behave and appear underwater in the open ocean? The Cousteau photographs will be invaluable in this respect for the student of cetacea, while for the layman they can only add to his fascination for these magnificent marine mammals of whose "bigness" he is already aware, but when he sees the picture of a diver alongside one of them he will realize their true dimensions.

There are some minor irritations; one or two of the captions are misleading and the Calypso crew demonstrate a little too often how photogenic they are. The Whale, Mighty Monarch of the Sea is one of a series being published by Cassell under the general title The Undersea Discoveries of Jacques$Y$ ves Cousteau, and I cannot help feeling that the author, or the publisher, has been in too much of a hurry to get this book, and the one that preceded it, into print. One can only hope that in the future Cousteau will be able to give more time to writing the text and produce a volume which will do him justice and perhaps emulate the quality of The Silent World.

\section{Sediment on the Move}

Mechanics of Sediment Transport. By M. S. Yalin. Pp. xii +290. (Pergamon: Oxford and New York, July 1972.) $\quad$ 99.

Although it is intended to give graduate students and research workers a guide to the extensive literature, this treatise is most notable for the proportion of hitherto unpublished analyses, interpretations and hypotheses, and of suggestions for future research programmes. One must therefore infer that the author's primary concern has been to attempt a dominating, and somewhat pre-emptive, guide to research, which may, in the future, be considered to have established significant trends. Only in the future will it be possible to assess the degree of success, but all research workers in sediment transport and related matters should find great interest and considerable value in the work.

After three introductory chapters, the remaining five chapters treat differing aspects of idealized sediment transport; initiation, rate, suspended load, sand waves and friction. Intentionally, but regtettably, there is little attempt to relate the new work contained in the treatise to practical situations, although river data are quoted. The author's background makes his complete avoidance of régime theory the more strange. It is in the generalization of the latter approach and its integration with the theory of idealized sediment transport, and with the findings from controlled experiment, that there is the greatest potential for advances of immediate significance in river mechanics.

Recurring throughout the book is the question of characteristic Shields dia. gram dip, and of its relationship with the Nikuradse uniform sand roughness form of transition. Now that the Nikuradse transition has been evaluated numerically, with a plausible physical argument for the form of transition control function, corresponding advances may be expected in the generalization of the Shields diagram and of similar findings.

I recommend a careful study of the work to all active research workers. It could also be of value in graduate studies but in conjunction with one, or both, of the other comprehensive English language texts which have been published within the last year or so.

D. I. H. BARR

\section{Erratum}

IN Nature $(240,243 ; 1972)$ the price of the book, Living on the Third Planet, by $H$. Alfvén and $K$. Alfvén, was given as $\$ 29$. The correct price is $£ 2.20$. 